\title{
SISTEMAS DE CONDUÇÃO PARA O CULTIVO DE Physalis NO PLANALTO CATARINENSE ${ }^{1}$
}

\author{
JANAÍNA MUNIZ², AIKE ANNELIESE KRETZSCHMAR ${ }^{3}$, LEO RUFATO ${ }^{4}$, \\ TÂNIA REGINA PELIZZA ${ }^{5}$, THIAGO MARCHI ${ }^{6}$, ALENCAR EUSÉBIO DUARTE $^{6}$, \\ ANA PAULA FERNANDES LIMA ${ }^{6}$, FERNANDA GARANHANI ${ }^{6}$
}

RESUMO - A cultura da Physalis peruviana, família das solanáceas, ainda é pouco explorada no Brasil, mas é uma nova opção de diversificação para pequenos produtores, com boas perspectivas para o mercado nacional e internacional, mais conhecida como camapum e joá-de-capote, podendo ser confundida com outras espécies. Essa frutífera pode chegar até dois metros de altura quando se utiliza um sistema de condução adequado, influenciando no desenvolvimento da planta e na qualidade do fruto produzido. O objetivo do trabalho foi avaliar a influência de quatro sistemas de condução de plantas de physalis na produção de frutos, em dois ciclos de produção, durante os anos de 2006-2007 e 2007-2008, em Lages-SC. Avaliaram-se os sistemas de condução em "V", em " $X$ ", espaldeira simples e livre. O delineamento experimental adotado foi de blocos ao acaso, com quatro repetições, sendo cada unidade experimental constituída de dez plantas. Observou-se que, nos dois ciclos consecutivos, o sistema em " $\mathrm{X}$ " apresentou os melhores resultados na maioria das características físico-químicas analisadas, quando comparado com os outros sistemas de condução. Conclui-se que a physalis se adapta bem à região do planalto catarinense e que, independentemente do sistema de condução utilizado, a planta tutorada sob sistema de condução apresentou frutos de maior peso, diâmetro e melhor qualidade, gerando frutos com maior valor comercial, quando comparados com a testemunha, sem condução e sem tutoramento.

Termos para indexação: Physalis peruviana L.; Condução; Manejo; Cultivo.

\section{CONDUCTION SYSTEMS FOR Physalis PRODUCTION IN SOUTHERN BRAZIL}

\begin{abstract}
The culture of Physalis peruviana, the Solanaceae family, is still little explored in Brazil, but is a new option for diversification for small farmers, with good prospects for the domestic and international markets. It is an exotic fruit, belonging to the nightshade family and is known as 'camapum' and 'joá-decapote', and can be confused with other species. It is a plant that can reach two meters in height when it is used an appropriate system, influencing plant development and quality of fruit produced. The objective was to evaluate the influence of four conduction systems in plants of Physalis in fruit production in two production cycles, during the years 2006-2007 and 2007-2008, in Lages, SC. It was evaluated the following conduction systems in "V", "X", simple and free espalier system. The experimental design was randomized blocks with four replicates and each experimental unit consisted of ten plants. It was observed that in two consecutive cycles, the " $\mathrm{X}$ " system showed the best results in most of the physico-chemical analysis, when compared with other conduction systems. It was conclude that the Physalis fits well the plateau region of Santa Catarina and that regardless of the conduction system used, the tutored plant under a conduction system had greater fruit weight, diameter and quality, thereby generating a result with higher commercial value.
\end{abstract}

Index terms: Physalis peruviana L.; Training, Management, Cultivation.

\footnotetext{
1(Trabalho 154-10). Recebido em: 22-06-2010. Aceito para publicação em: 03-02-2011.

${ }^{2}$ Economista, Mestranda em Produção Vegetal, CAV/UDESC. Bolsista de Pesquisa CNPq. Lages - SC, janainamuniz@gmail.com, ${ }^{3}$ Dra. Fruticultura, Orientadora, Professora do Departamento de Agronomia, CAV/UDESC. Lages - SC. E-mail: a2aak@cav.udesc.br ${ }^{4}$ Dr. Fruticultura, Co-orientador, Professor do Departamento de Agronomia, CAV/UDESC. Lages-SC. Bolsista de Produtividade em Pesquisa do CNPq. E-mail: leoruffato@yahoo.com.br

${ }^{5}$ Pós-doutoranda, CAV/UDESC, Bolsista PRODOC/CAPES. Lages - SC. E-mail: trp_mestagro@hotmail.com

${ }^{6}$ Acadêmicos do Curso de Agronomia, CAV/UDESC. Lages - SC.E-mail: marchithiago@yahoo.com.br; alencareuzebioduarte@yahoo.com.br; ear_ana@hotmail.com; nandagaranhani@hotmail.com
} 


\section{INTRODUÇÃO}

O cultivo de pequenas frutas no Brasil tem despertado a atenção de produtores, comerciantes e consumidores, especialmente nos últimos anos. A inserção das pequenas frutas, como atividade econômica, é ainda bastante incipiente e inovadora, caracterizando-se, de modo geral, pelo baixo custo de implantação e de produção, acessível aos pequenos produtores, bom retorno econômico em curto prazo, boa adaptação às condições socioeconômicas e ao ambiente local, grande exigência de mão de obra, possibilidade de cultivo no sistema orgânico e demanda maior do que a oferta (POLTRONIERI, 2003). Nesse aspecto, a Physalis (Physalis peruviana L.) surge como uma opção interessante de cultivo para o planalto catarinense.

Segundo Chaves (2006), a Physalis é uma frutífera de grande valor nutricional e econômico que está sendo incorporada no quadro das pequenas frutas no Brasil, onde a Physalis é popular no Norte e Nordeste, mas é novidade nas regiões Sul e Sudeste. Ela pode ser encontrada nos mercados locais, principalmente em São Paulo e Rio de Janeiro, mas ainda tem sido importada da Colômbia a preços elevados, pois a produção brasileira ainda é pequena (RODRIGUES et al., 2009).

Conforme González et al. (2008), a physalis cresce como planta silvestre nas zonas tropicais da América, tendo como centro de origem os países Andinos, principalmente a Colômbia, Peru e Equador. Essa frutífera tem provocado algumas confusões na literatura, devido à diversidade de nomes comuns existentes, sendo às vezes confundida com outras espécies. Na Colômbia, é conhecida como uchuva e no Japão como hosuki, enquanto no Brasil é conhecida principalmente como camapum e joá-de-capote.

Para Velasquez et al. (2007), o cultivo dessa frutífera é uma alternativa de economia agrícola, com boas perspectivas de comercialização no mercado nacional e internacional, devido ao elevado conteúdo nutracêutico. Embora o cultivo dessa fruta apresente um grande potencial para a região do planalto catarinense, graças ao seu alto valor agregado, seu plantio ainda é restrito em decorrência do desconhecimento de práticas de manejo cultural, alta demanda de mão de obra e a logística entre a colheita e o mercado. Os preços elevados fazem com que seu consumo fique restrito a um nicho de mercado para pessoas com maior poder aquisitivo, podendo, no pico da safra, ter seus preços reduzidos, ficando acessíveis a uma maior faixa de consumidores.

Com um manejo adequado e planejado, o cultivo pode permanecer em produção por até 2 anos, de acordo com a região e o clima predominante. Porém, a partir do segundo ano, existe uma redução da produtividade como também da qualidade dos frutos. A utilização de técnicas adequadas de manejo da cultura, como adubação, espaçamento, tutoramento, desbaste, condução, poda, dentre outras práticas culturais, contribuem para melhorar a qualidade e a aparência da Physalis.

Em geral, o espaçamento mais indicado no plantio da Physalis é de 1 a $2 \mathrm{~m}$ entre plantas e 2 a 3 $\mathrm{m}$ entre filas, sendo possível diminuir a distância entre plantas de 0,50 a 1,5 m, quando se utiliza algum tipo de sistema de condução. Porém, a topografia do terreno é o aspecto que mais influencia na definição da distância entre as mudas, pois tem um papel importante na aeração, umidade e tratos culturais (RUFATO et al., 2008).

Segundo Zapata et al. (2002), recomenda-se utilizar um sistema de condução, pois quando a planta está em plena produção, alcança elevada massa nos ramos, o que causa tombamento e quebra de galhos, além de dificultar os tratos culturais. Há vários sistemas de condução para o cultivo da Physalis, sendo os principais em "V", em " $\mathrm{X}$ " e espaldeira simples (RUFATO et al., 2008). Conforme Salazar et al. (2008), o sistema de condução em forma de "V" é o sistema mais utilizado na Colômbia.

O tipo de tutoramento utilizado pode alterar a distribuição da radiação solar e a ventilação em torno das plantas (ANDRIOLO, 1999), influenciando na umidade relativa e na concentração de gás carbônico atmosférico entre e dentro das fileiras (GEISENBERG; STEWART, 1986), contribuindo desta maneira para a produção de frutos de maior tamanho e de melhor qualidade.

Historicamente, o aumento do rendimento das culturas tem-se constituído numa das metas mais perseguidas pela pesquisa, na busca da modernização e da maior eficiência do processo de produção agrícola (PEREIRA, 2008). Isso ressalta a grande importância de se escolher e adotar um sistema de condução que permita melhor aeração entre as plantas e melhor aproveitamento da luminosidade, contribuindo para o crescimento e o desenvolvimento da planta, havendo equilíbrio entre a parte vegetativa e a produtiva, produzindo frutos de maior tamanho e qualidade, $\mathrm{e}$ aumentando o rendimento da cultura.

Tendo em vista a importância dessa cultura como uma alternativa de produção para os pequenos e médios produtores e também à falta de informações disponíveis sobre o seu comportamento na região Sul do Brasil, o presente trabalho teve como objetivo avaliar o cultivo da Physalis no planalto catarinense em diferentes sistemas de condução. 


\section{MATERIAIS E MÉTODOS}

O experimento foi conduzido no pomar experimental do Centro de Ciências Agroveterinárias da Universidade do Estado de Santa Catarina (UDESC), na cidade de Lages, coordenadas geográficas de $27^{\circ}$ $48^{\prime}$ latitude sul e $50^{\circ} 19^{\prime}$ 'longitude oeste, com altitude média de $916 \mathrm{~m}$. Na Tabela 1, são apresentados os valores médios de temperatura, umidade relativa $\mathrm{e}$ precipitação ocorridos na região de Lages-SC, durante os ciclos produtivos de 2006-2007 e 2007-2008.

O local de plantio foi adubado e corrigido de acordo com a necessidade indicada pela análise de solo. A recomendação de adubação foi realizada utilizando-se como padrão da cultura do tomateiro, para uma expectativa de $20 \mathrm{t} \mathrm{ha}^{-1}$.

Utilizaram-se plantas de Physalis peruviana L., obtidas através de sementes. O transplante para o local definitivo, no ciclo de 2006-2007 foi realizado dia 10 de outubro, e no ciclo de 2007-2008 em 10 de novembro, quando as plantas apresentavam aproximadamente $15 \mathrm{~cm}$ de comprimento.

O delineamento experimental adotado foi o de blocos ao acaso, com quatro tratamentos e quatro repetições, sendo cada unidade experimental constituída de dez plantas. Os tratamentos foram compostos pelos seguintes sistemas de condução: sistema em "V", sistema em "X", espaldeira simples e sistema livre, avaliados em dois ciclos agrícolas (2006-2007 e 2007-2008). O espaçamento adotado para todos os tratamentos foi de $1,00 \mathrm{~m}$ entre plantas e 3,00 m entre filas.

Na Figura 1, são apresentadas as ilustrações dos sistemas de condução utilizados no experimento. O sistema em "V" consistiu em conduzir duas hastes principais com fitilhos de polietileno, inclinados com ângulo de $60^{\circ}$, presos em um fio de arame com altura do chão de $1,70 \mathrm{~m}$. No sistema em " $X$ ", quatro ramos principais foram definidos e, então, amarrados com fitilhos e esticados em lados opostos, em um fio de arame a 1,70 m do chão. No sistema em espaldeira simples, utilizaram-se palanques de $1,50 \mathrm{~m}$, prendendo os fios de arame a duas alturas do chão, $0,50 \mathrm{~m}$ e 1,20 m, nos quais foram selecionados seis ramos principais e tutorados também com fitilho. A testemunha, denominada sem condução ou sistema livre, consistiu em não utilizar qualquer tipo de tutoramento, deixando-se as plantas crescerem naturalmente.

Nas plantas tutoradas e sob sistema de condução, realizou-se a poda de formação quando a planta estava com $45 \mathrm{~cm}$ de altura, sendo também realizada quinzenalmente a desbrota. No sistema livre, nenhuma dessas práticas foi realizada.

A colheita dos frutos foi realizada semanal- mente, sendo que no ciclo de 2006-2007, iniciou-se no dia 21 de dezembro de 2006 e estendeu-se até 10 de maio de 2007. No ciclo de 2007-2008, a colheita iniciou-se no dia 19 de janeiro de 2008 e teve seu término dia 27 de maio de 2008 . A produção de frutos, nos dois ciclos, encerrou-se com as primeiras geadas, com temperaturas abaixo de $-2^{\circ} \mathrm{C}$.

O ponto de colheita foi determinado de acordo com a Norma Técnica Colombiana $\mathrm{n}^{\circ} 4.580$, de 1999, do Instituto Colombiano de Normas Técnicas. Dessa forma, em ambos os ciclos de produção, os frutos foram colhidos a partir da coloração do cálice amarelo-esverdeado e a coloração alaranjada da epiderme da fruta.

Para as análises laboratoriais, utilizaram-se amostras de 25 frutas por colheita de cada parcela. As variáveis analisadas durante a condução do experimento foram: peso médio do fruto $(\mathrm{g})$, diâmetro médio do fruto $(\mathrm{mm})$, teor de sólidos solúveis ( $\left.{ }^{\circ} \mathrm{Brix}\right)$, determinado por refratometria, com correção de temperatura para $20^{\circ} \mathrm{C}$, e a produtividade estimada em toneladas por hectare.

Os dados foram submetidos à análise da variância, pelo teste $\mathrm{F}$, e as médias, analisadas pelo teste de Tukey, a 5\% de probabilidade de erro.

\section{RESULTADOS E DISCUSSÃO}

Com relação à variável peso do fruto, observa-se na Figura 2, no ciclo de 2006-2007 e 20072008 , que as plantas conduzidas no sistema em " $X$ " produziram frutos com valores superiores aos dos demais sistemas, e neste último ciclo apresentaram um aumento de aproximadamente $14 \%$ em relação ao ciclo produtivo anterior. Frutos com menor peso foram observados nos sistemas de condução em espaldeira simples e sistema livre, para os dois ciclos consecutivos de produção de Physalis, na região de Lages-SC.

Conforme Lima (2009), o maior resultado verificado para essa variável foi no sistema de tutoramento triangular; entretanto, esses resultados não diferiram do sistema de tutoramento "V" invertido. Frutos com menor peso foram obtidos nos sistemas de tutoramento verticais.

Em outras culturas, como o tomateiro, citado por Marin et al. (2005), os sistemas de tutoramento verticais podem proporcionar aumento de peso dos frutos em torno de 6 a $20 \%$ em relação aos sistemas "V" invertido e triangular, respectivamente. Há poucas referências sobre trabalhos com tutoramento de Physalis, e os registros de pesos de frutos variam de 4 a $10 \mathrm{~g}$ (FISCHER; ALMANZA, 1993) e de 3,08 a 3,92 g (NIÑO et al., 2008). Nas condições de Zamo- 
rano, em Honduras, registrou-se o peso do fruto entre 2,01 g e 3,41 g, com um peso médio de 2,63 g cada fruto, com cálice e pedúnculo (SÁNCHEZ, 2002).

Cada fruta de Physalis pode atingir peso entre 3 a $10 \mathrm{~g}$ (ICONTEC, 1999). De acordo com os resultados observados neste experimento, somente os frutos produzidos sob o sistema de condução em espaldeira não se encaixam dentro dos valores obtidos nas principais regiões produtoras da $\mathrm{Co}-$ lômbia, sendo que, em todos os demais sistemas de condução, foram obtidos resultados satisfatórios nos dois ciclos agrícolas.

Na Figura 3, observa-se que os melhores resultados para a variável diâmetro de frutos no ciclo de 2006-2007 ocorreram no sistema em "X", com diâmetro de 18,63 mm, havendo diferença significativa em relação aos demais sistemas adotados. No ciclo de 2007-2008, o sistema em "X" apresentou valores semelhantes ao sistema "V", com diâmetros de 19,37 mm e 19,32 mm, respectivamente, enquanto o sistema em espaldeira mostrou o menor diâmetro de frutos $(13,65 \mathrm{~mm})$.

Tais resultados são importantes para o produtor, pois geralmente os frutos frescos e de tamanho maior são aqueles mais atrativos para os consumidores e alcançam os melhores preços nos mercados (MERCEDES; MARGARITA, 2004).

Tratando-se de classificação de frutos, o Instituto Colombiano de Normas Técnicas (1999) classifica os frutos de Physalis em 4 classes quanto ao diâmetro: Classe "A"-de 15 a $18 \mathrm{~mm}$; Classe "B"-de 18,1 a 20 mm; Classe "C"-de 20,1 a 22 mm; e Classe "D"-acima de $22 \mathrm{~mm}$.

No primeiro ciclo agrícola de 2006-2007, somente os frutos produzidos no sistema em " $\mathrm{X}$ " se enquadram na classe "B"; nos demais sistemas, os frutos produzidos enquadram-se na classe " $A$ ", ou seja, com menores valores de diâmetro. No segundo ciclo agrícola de 2007-2008, os frutos produzidos nos sistemas "V", "X" e livre também se enquadram na Classe "B", mas o sistema espaldeira apresentou os menores valores de diâmetro, sendo que os frutos não se enquadram em nenhuma classe de calibre.

De acordo com Lima (2009), os frutos de maior diâmetro produzidos em Pelotas-RS, enquadram-se na Classe "B", nos sistemas de condução triangular e "V" invertido, sendo que, no sistema vertical, os frutos foram incluídos na classe "A".

Na Figura 4, observa-se que os maiores valores de produtividade no ciclo de 2006-2007 ocorreram em plantas conduzidas no sistema em espaldeira simples, seguido do sistema em "V". Entretanto, no ciclo de 2007-2008, houve maior produtividade das plantas conduzidas sob o sistema em "X". É possível também observar que a produtividade da testemunha, nos dois ciclos agrícolas, foi menor que os dos demais sistemas.

Conforme Lima (2008), os maiores valores de produtividade foram observados no sistema "V" invertido $\left(9,72 \mathrm{tha}^{-1}\right)$, sendo que o sistema vertical e o triangular resultaram em valores inferiores ao esperado para a cultura, 4,53 e 8,54 $\mathrm{tha}^{-1}$, respectivamente.

De forma geral, os valores de produtividade observados neste experimento estão dentro do esperado para a cultura, pois, segundo Brito (2002), a produtividade na Colômbia é em média de 10 a $15 \mathrm{t} \mathrm{ha}^{-1}$ em dois anos consecutivos. Entretanto, a Corporación Colombiana Internacional (2000) relata produtividades de até $20 \mathrm{t} \mathrm{ha}^{-1}$, porque naquele País o período útil de produção das plantas é de 5 a 11 meses. Conforme Neremberg (2000), no Equador, a produção não excede a 12 t ha ${ }^{-1}$ e segundo Rodriguez (1995), na Nova Zelândia, a produtividade média é de 8 a 12 t ha $^{-1}$, enquanto na Alemanha, conforme Obrecht (1993), a produtividade experimental está entre 5 a $9 \mathrm{tha}^{-1}$.

As produtividades alcançadas no experimento foram relativamente menores que as observadas nas principais regiões produtoras da Colômbia, devido, provavelmente, ao ciclo produtivo da cultura da Physalis no planalto catarinense ser bem menor. Nessa região, o ciclo produtivo limita-se a apenas sete meses, pois a partir de maio ocorrem baixas temperaturas, inviabilizando o cultivo, enquanto nas regiões produtoras da Colômbia a colheita é realizada ao longo de dois anos consecutivos.

Para a variável sólidos solúveis (Figura 5), as maiores médias ocorreram no sistema de condução em espaldeira simples, nos dois ciclos consecutivos de cultivo da Physalis. No ciclo de 2006-2007, o valor de sólidos solúveis dos frutos no sistema espaldeira foi significativamente superior aos dos demais sistemas de condução estudados. No ciclo de 2007-2008, não houve diferença significativa entre os sistemas de condução em "V", em " $X$ " e espaldeira. Os menores valores observados de sólidos solúveis foram de 9,23 ${ }^{\circ}$ Brix no ciclo de 2006-2007 no sistema em " $X$ " e de 9,93 ${ }^{\circ}$ Brix no ciclo de 2007-2008 na testemunha.

De acordo com as normas do Codex Stan (2005), os frutos de Physalis devem apresentar teor de sólidos solúveis de, no mínimo, $14{ }^{\circ}$ Brix para serem comercializados na Colômbia; portanto, os frutos produzidos em Lages apresentaram valores de sólidos solúveis próximos aos permitidos para a comercialização. Entretanto, vale ressaltar que esse parâmetro não pode ser observado isoladamente, pois devem ser analisados outros atributos na hora da comercialização, como, por exemplo, o peso, a colo- 
ração, o diâmetro e a qualidade do fruto produzido.

Rodriguez (1995), em Santiago no Chile, verificou valores de sólidos solúveis de $12,1^{\circ} \mathrm{Brix}$ em frutos oriundos de plantas tutoradas no sistema espaldeira, os quais também não se enquadrariam dentro das normas do Codex Stan (2005). Além disto, esses valores variam conforme as condições climáticas de cada região de cultivo.

Lima (2009), em trabalho com diferentes colorações de cálice e sistemas de condução de $P h y$ salis, verificou diferenças significativas de sólidos solúveis conforme a coloração do cálice dos frutos, porém houve semelhança entre as médias conforme os sistemas de condução utilizados. Frutos colhidos nas fases de amarelo-esverdeados a amarelo-amarronzados, produzidos nos sistemas de condução em "V" invertido e triangular, poderiam ser comercializados (14,36 a 15,30 ${ }^{\circ}$ Brix), com exceção da fase de coloração verde, onde, no sistema "V" invertido, observou-se menor valor de sólidos solúveis $(10,86$ ${ }^{\circ}$ Brix) dos frutos produzidos em Pelotas-RS.

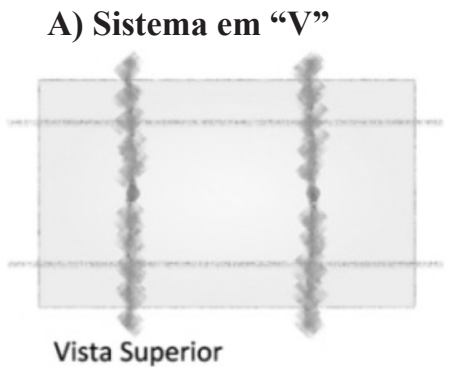

B) Sistema em " $X$ "

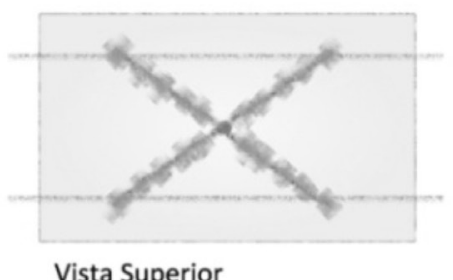

Vista Superior

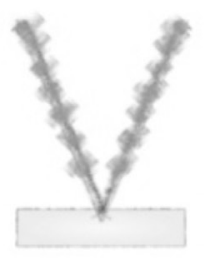

- 1 planta

-2 ramos

- bambu para

sustentação

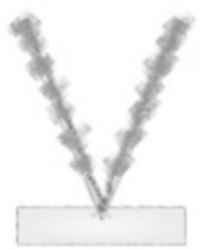

Vista Frontal
- 1 planta

-4 ramos

- bambu para sustentação

C) Sistema em Espaldeira

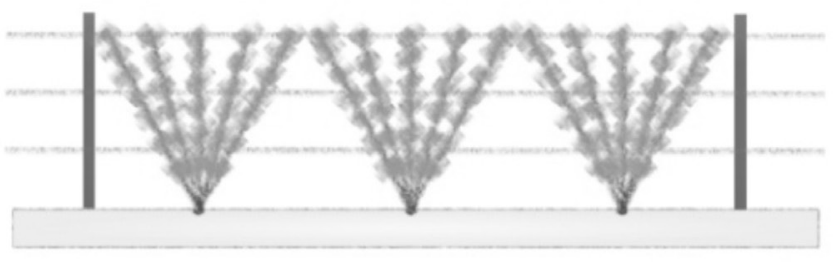

Vista Lateral

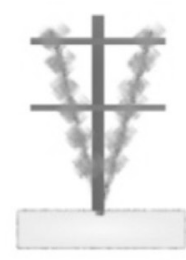

Vista Frontal

\section{D) Testemunha}
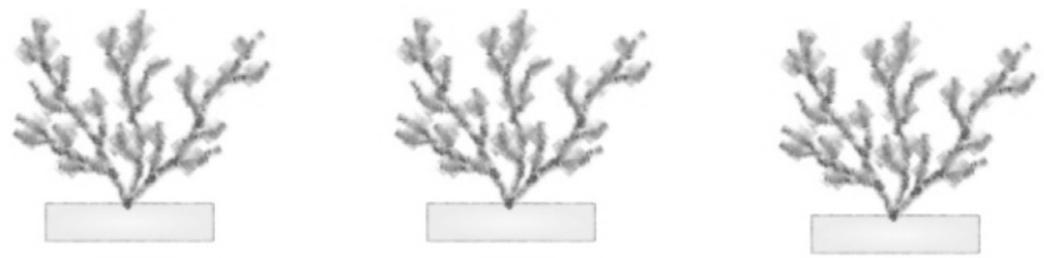

FIGURA 1 - Sistemas de condução para Physalis peruviana L. A) Sistema "V”, B) Sistema "X", C) Espaldeira e D) Sistema Livre. Lages-SC. Diagrama: Jeremias Formolo . 


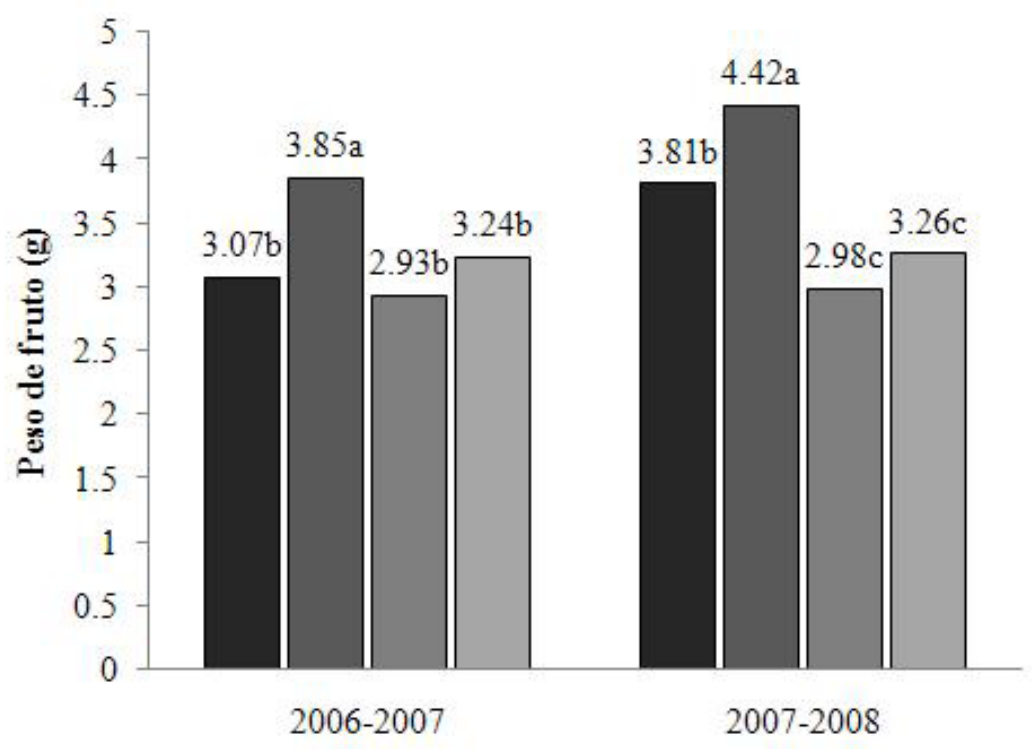

- Sistema V $\square$ SistemaX $\quad$ Espaldeira $\square$ Testemunha

FIGURA 2 - Peso do fruto de Physalis peruviana L., sem cápsula (g), produzido em diferentes sistemas de condução, nos ciclos de 2006-2007 e 2007-2008. Lages-SC.

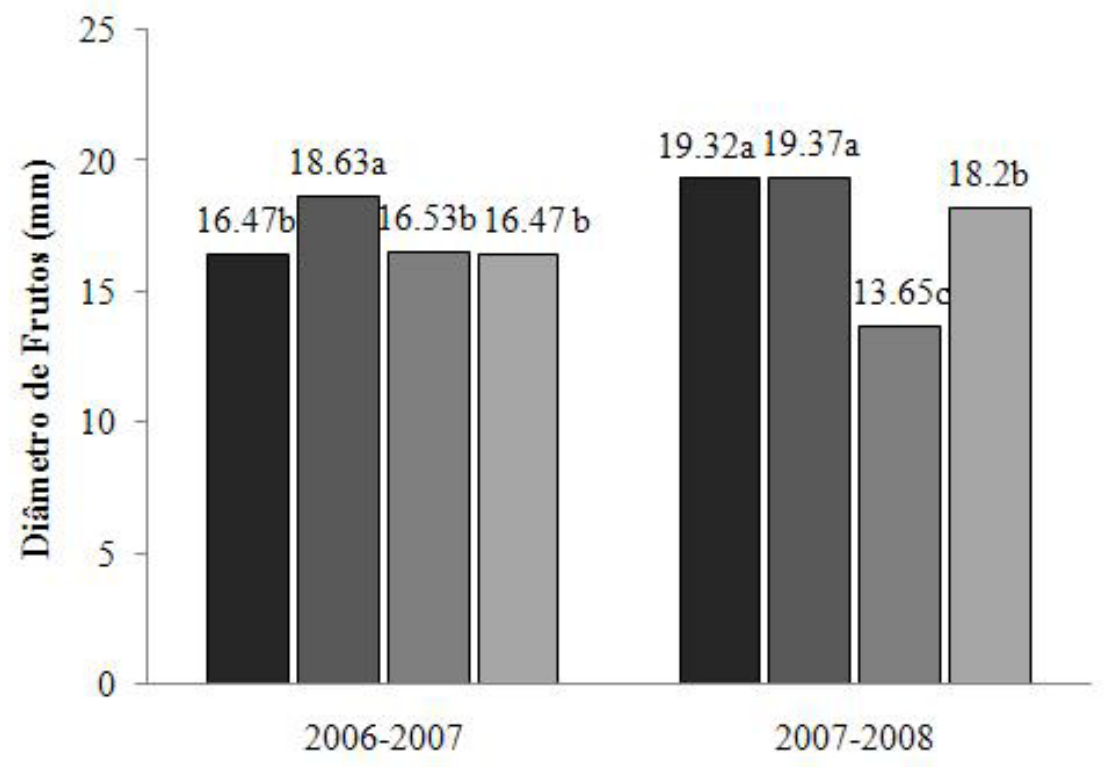

- Sistema V $\square$ Sistema X $\quad$ Espaldeira $\square$ Testemunha

FIGURA 3 - Diâmetro do fruto de Physalis peruviana L., produzido em diferentes sistemas de condução, nos ciclos de 2006-2007 e 2007-2008. Lages-SC. 


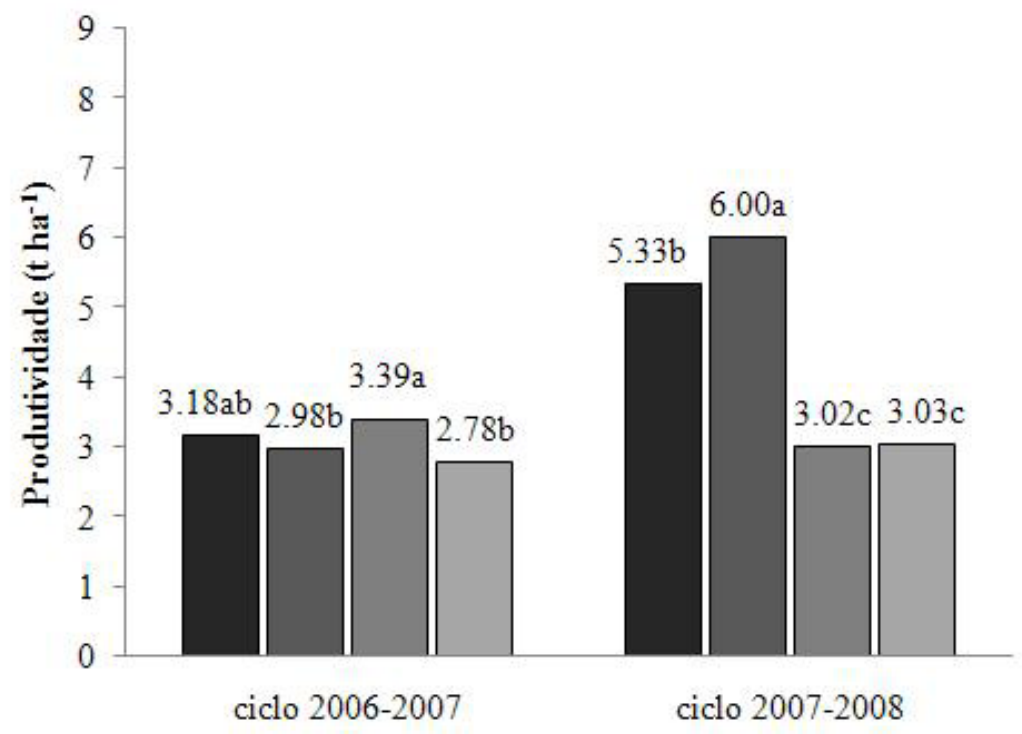

- Sistema V $\quad$ Sistema X घEspaldeira $\quad$ Testemunha

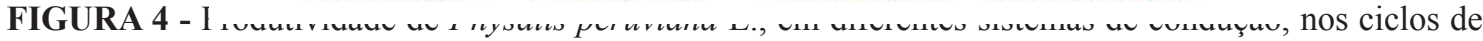
2006-2007 e 2007-2008. Lages-SC.

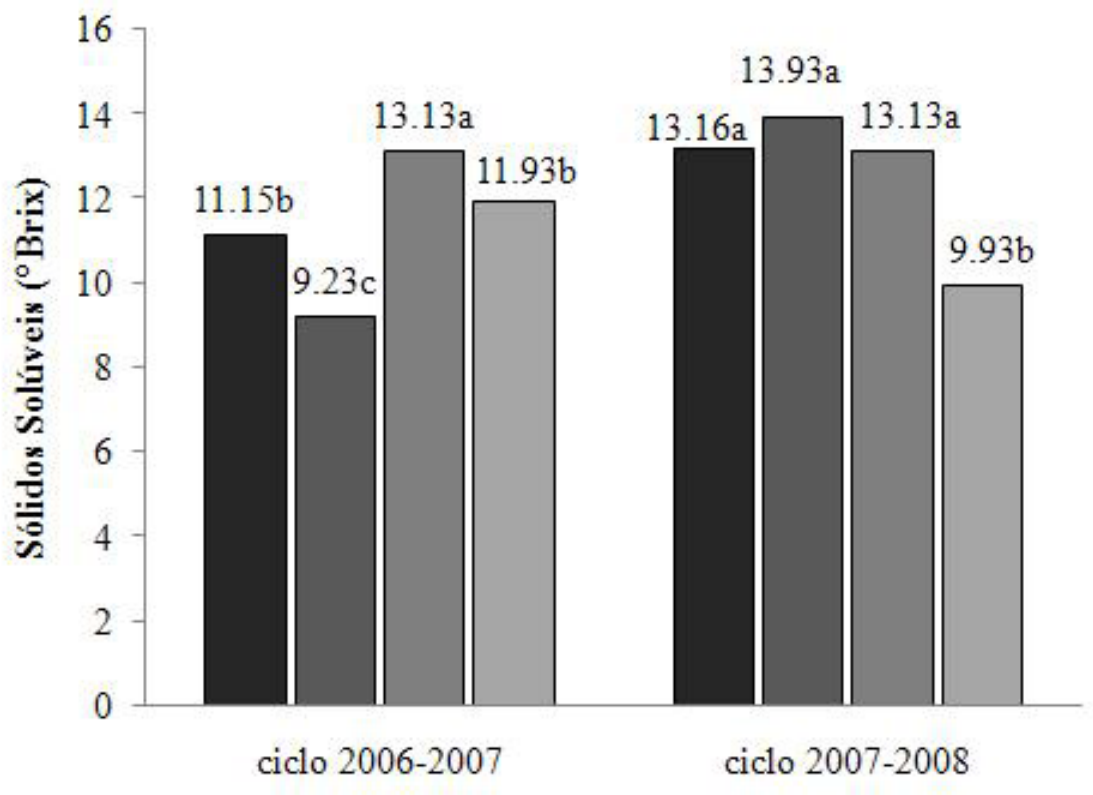

- Sistema V $\square$ Sistema $\mathrm{X}$ घEspaldeira $\square$ Testemunha

FIGURA 5 - Sólidos solúveis de frutos de Physalis peruviana L., produzidos em diferentes sistemas de condução, nos ciclos de 2006-2007 e 2007-2008. Lages-SC. 
TABELA 1 - Valores médios de temperatura, umidade relativa e precipitação ocorridos na região de LagesSC, durante os ciclos produtivos de physalis 2006-2007 e 2007-2008.

\begin{tabular}{|c|c|c|c|c|c|c|c|c|}
\hline Ano & \multicolumn{3}{|c|}{2006} & \multicolumn{5}{|c|}{2007} \\
\hline Mês & Outubro & Novembro & Dezembro & Janeiro & Fevereiro & Março & Abril & Maio \\
\hline Temperatura $\left({ }^{\circ} \mathrm{C}\right)$ & 17.5 & 17.3 & 21.2 & 21.1 & 20.6 & 21.7 & 18.3 & 12.5 \\
\hline Umidade Relativa (\%) & 84.8 & 81.3 & 83.1 & 84.7 & 84.3 & 84.8 & 87.0 & 88.4 \\
\hline Precipitação (mm) & 73.1 & 250.9 & 128.5 & 110.0 & 128.7 & 164.6 & 64.5 & 180.4 \\
\hline Ano & & 2007 & & & & 2008 & & \\
\hline Mês & Outubro & Novembro & Dezembro & Janeiro & Fevereiro & Marco & Abril & Maio \\
\hline Temperatura $\left({ }^{\circ} \mathrm{C}\right)$ & 17.1 & 17.4 & 18.7 & 20.5 & 20.3 & 19.5 & 15.9 & 13.1 \\
\hline Umidade Relativa (\%) & 88.8 & 80.4 & 79.6 & 82.2 & 77.7 & 81.9 & 77.7 & 79.0 \\
\hline Precipitacão (mm) & 190.3 & 141.9 & 99.2 & 166.1 & 118.2 & 79.7 & 177.5 & 55.4 \\
\hline
\end{tabular}

Dados oriundos da Estação Experimental no Centro de Ciências Agroveterinárias da Universidade do Estado de Santa Catarina, Lages-SC.

\section{CONCLUSÕES}

Baseados nos dois ciclos agrícolas de cultivo da Physalis peruviana L. no planalto catarinense, conclui-se que:

1-Os sistemas de condução influenciam no desenvolvimento das plantas e no tamanho e qualidade do fruto produzido.

2-O sistema de condução em " $X$ " é o mais indicado para o cultivo de Physalis no planalto catarinense.

3-Para se obter maior produtividade e melhor qualidade dos frutos, é necessário utilizar sistema de condução, com poda e tutoramento das plantas.

\section{AGRADECIMENTOS}

- À Instituição de Pesquisa CAV-UDESC, onde foi realizado o experimento.

- Ao Conselho Nacional de Desenvolvimento Científico e Tecnológico - Brasil, pela concessão da Bolsa de Pesquisa.

\section{REFERÊNCIAS}

ANDRIOLO, J.L. Fisiologia das culturas protegidas. Santa Maria: UFSM, 1999. 142p.

BRITO, D.F.M. Producción de uvilla para exportación. Quito: Fundación Ecuatoriana de Tecnologia Apropiada, 2002. 10p.
CHAVES, A.C. Propagação e avaliação fenológica de Physalis sp. na região de Pelotas-RS. 2006. Tese (Doutorado) - Universidade Federal de Pelotas, Pelotas, 2006. 65p.

CODEX STAN. Norma del codex para La uchuva. México, 2005. 14p.

CORPORACIÓN COLOMBIA INTERNACIONAL, UNIVERSIDAD DE LOS ANDES Y DEPARTAMENTO DE PLANEACIÓN NACIONAL. Análisis internacional del sector hortofrutícola para Colombia. Bogotá: Editorial El Diseño, 2000.

FISCHER, G.; ALMANZA, P.J. Nuevas tecnologías en el cultivo de la uchuva Physalis peruviana L. Revista Agrodesarrollo, Tunja, v.4, n.1-2, p. 294, 1993.

GEISENBERG, C.; STEWART, K. Field crop management. In: ATHERTON, J.G.; RUDICH, J. (Ed.). The tomato crop. London: Chapman \& Hall, 1986.

GONZÁLEZ, O.T.; TORRES J.M.C.; CANO C.I.M.; ARIAS M.L.; ARBOLEDAA.A.N. Caracterización morfológica de cuarenta y seis accesiones de uchuva (Physalis peruviana L.), en Antioquia (Colombia). Revista Brasileira de Fruticultura, Jaboticabal, v.30, n.3, p. 708-715, 2008.

ICONTEC - Instituto Colombiano de Normas Técnicas y Certificación. Norma técnica colombiana uchuva NTC 4580. Bogotá, 1999. 15p. 
LIMA, C.S.M. Fenologia, sistemas de tutoramento e produção de Physalis peruviana na região de Pelotas-RS. 2009. 117f. Dissertação (Mestrado) Universidade Federal de Pelotas, Pelotas. 2009.

LIMA, C.S.M.; SEVERO, J.; MANICA-BERTO, R.; SILVA, J.A.; RUFATO, L.; RUFATO, A.R. Características físico-químicas de physalis em diferentes colorações do cálice e sistemas de condução. Revista Brasileira de Fruticultura, Jaboticabal, v.31, n.3, p.1062-1065, 2009.

MARIM, B.G.; SILVA, D.J.H.; GUIMARÃES, M.A.; BELFORT, G. Sistemas de tutoramento e condução do tomateiro visando à produção de frutos para consumo in natura. Horticultura Brasileira, Brasília, v.23, p.951-955, 2005.

MERCEDES, M.C.; MARGARITA, M.D. Plan exportador, logistico y de comercializacion de uchuva al mercado de estados unidos para FRUTEXPO.S.C.I. LTDA. 2004. 134f. Monografia (Trabalho de Graduação) - Faculdad de Ingenieria, Pontificia Universidad Javeriana, Bogotá, 2004.

NEREMBERG, F.A. Comportamiento agronomico de Physalis peruviana L., proviniente de semillas y estabelecida en distintas conduccion. 2000. 112f. Tesis (Doutorado) - Faculdad de Ciencias Agricolas, Universidad Central Del Ecuador, Quito, 2000.

NIÑO, N.E.; ARBELÁEZ, G.; NAVARRO R. Efecto de diferentes densidades poblacionales de Meloidogyne hapla sobre uchuva (Physalis peruviana L.) en invernadero. Revista Agronomía Colombiana, Bogotá, v.26, n.1, p.58-67, 2008.

OBRECHT, A.S. Estudio fenologico de uvilla (Physalis peruviana L.). 1993. 71f. Tesis (Doutorado) - Faculdad de Ciencias Agrarias e Forestales, Universidad de Chile, Santiago, 1993.

PEREIRA, I. DOS S. Adubação de pré-plantio no crescimento, produção e qualidade da amoreirapreta (Rubus sp.). 2008. 149f. Dissertação (Mestrado em Agronomia) - Faculdade de Agronomia Eliseu Maciel, Universidade Federal de Pelotas, Pelotas, 2008.
POLTRONIERI, E. Alternativas para o mercado interno de pequenas frutas. In: I Seminário Brasileiro sobre pequenas frutas, 1., 2003, Vacaria. Anais... Bento Gonçalves: Embrapa Uva e Vinho, 2003. p.37-40. (Documenos, 37)

RODRIGUEZ, C.D.L. Efectos de la conduccion y fertilizacion sobre La producion, crecimiento e desarrollo em uvilla. 1995. 76f. Monografia (Trabalho de Graduação em Agronomia) - Faculdad de Ciencias Agrarias e Forestales, Universidad de Chile, Santiago, 1995.

RODRIGUES, E.; ROCKENBACH, I. I.; CATANEO, C.; GONZAGA, L. V.; CHAVES, E. S.; FETT, R. Minerals and essential fatty acids of the exotic fruit Physalis peruviana L. Ciência e Tecnologia de Alimentos, Campinas, v.29, n.3, p.642-645, 2009.

RUFATO, L.; RUFATO, A.R.; SCHLEMPER, C.; LIMA, C.S.M; KRETZSCHMAR, A.A. Aspectos técnicos da cultura da Physalis. Lages: CAV/ UDESC; Pelotas: UFpel, 2008. 100p.

SALAZAR, M.R.; JONES, J.W.; CHAVES B.; COOMAN A.; FISCHER, G. Base temperature and simulation model for nodes appearance in cape gooseberry (Physalis peruviana L.). Revista Brasileira de Fruticultura, Jaboticabal, v.30, n.4, p.862-867, 2008.

SÁNCHEZ, J.P.S. Estudios fenológicos de uchuva (Physalis peruviana L.) en El Zamorano. 2002. 29f. Monografia (Trabajo de Graduación el Ingeniero Agrónomo) - Grado Académico de Licenciatura, Honduras, 2002.

VELASQUEZ, H.J.C.; GIRALDO, O.H.B.; ARANGO, S.S.P. Estudio preliminar de La resistencia mecánica a la fractura y fuerza de firmeza para fruta de uchuva (Physalis peruviana L.) Revista Facultad Nacional de Agronomía, Medellín, v.60, n.1, p.3785-3796, 2007.

ZAPATA, J. L.; SALDARRIAGA, A.; LONDOÑO, M.; DIAZ, C. Manejo del cultivo de la uchuva en Colombia. Antioquia: Corporación Colombiana de Investigación Agropecuaria, 2002. 40p. (Boletim Técnico) 